\title{
La evaluación comunitaria: una herramienta de integración social en los habitantes de la comunidad "Arcoíris"
}

\author{
The community evaluation: an implement of social integration in \\ inhabitants from "Arcoíris" community

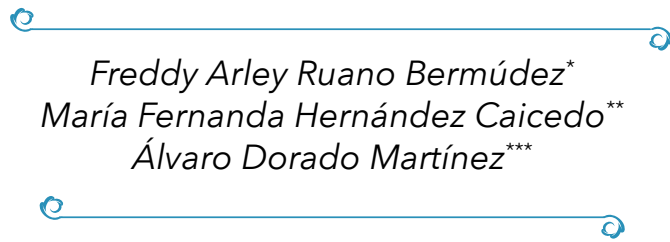

Recibido 15. 04. 2019• Arbitrado 18. 05. $2019 \bullet$

Aprobado 25.06. 2019

* Psicólogo, Universidad de Nariño, Pasto - Colombia, Grupo de investigación Libres Pensadores, ORCID: 0000-0002-4888-711X, freddyarleyr@ gmail.com

** Psicóloga, Universidad de Nariño, Pasto - Colombia, Grupo de investigación Psicología y Salud, ORCID: 0000-0002-6169-3352, mfernanda061109@gmail.com

*** Magister en Psicología Universidad Autónoma de México, Grupo de investigación Psicología y Salud, ORCID: 0000-0002-9879-5109, alvarodoradomartinez@gmail.com

\section{Resumen}

La evaluación comunitaria es un elemento que ha permitido realizar lecturas a profundidad de la realidad social, para generar acciones colectivas acordes a las necesidades comunitarias y posibiliten su integración social. Por tanto, el presente artículo de investigación expone el desarrollo del proceso de evaluación comunitaria en habitantes de la comunidad Arcoíris; quienes han sido parte del conflicto armado de Colombia. La investigación se llevó a cabo bajo la metodología cualitativa y enfoque histórico hermenéutico, las técnicas empleadas fueron la entrevista semiestructurada, grupo focal, mapeo comunitario y observación participante. Los resultados evidenciaron que la comunidad comparte un espacio geográfico, configurado como el escenario de las acciones y los procesos comunitarios, el cual posibilita la creación de actitudes, costumbres y formas lingüísticas propias, determinadas a partir de su historia y que favorecen la identificación, el análisis de su realidad y la creación de estrategias a favor de su transformación social.

Palabras clave: Comunidad, transformación social, participación, necesidad social. 


\section{Abstract}

The community evaluation is an element that has made it possible to carry out detailed readings and analyses of the social reality to generate collective actions according to the community needs, therefore the objective of this article is to develop the community assessment process in inhabitants from "Arcoíris" community that has been part of the armed conflict in Colombia. The research was developed under the qualitative methodology and the historical hermeneutical approach, the techniques used were the semi-structured interview, focus group, community mapping and participant observation. The results showed that the community shares a geographical space, configured as the scene of community actions and processes, concluding that it allows the creation of attitudes, customs and linguistic forms, determined from their history and that favor identification, the analysis of their reality and the creation of strategies that provide a solution to their problems.

Key words: Comunity, social transformation, participation, social need.

\section{Introducción}

La evaluación comunitaria se ha constituido como un proceso de adquisición, análisis y presentación de la realidad socio-histórica de una comunidad que permite evidenciar sus fortalezas y recursos, brindando un panorama detallado de las necesidades comunitarias para crear acciones conjuntas que las fortalezcan. Ésta, se ha convertido en fuente de transformación social, al ser las mismas comunidades quienes lideran y promueven sus propios cambios (Carroll y Peréz, 2004). En este sentido, la evaluación comunitaria es un potencial de recuperación de la historia colectiva que implica consecuencias para las acciones políticas y que por su razón van más allá de las teorías científicas que la soportan, ya que por medio de este proceso participativo se desarrolla una conciencia histórica que rescata opiniones personales a favor de una acción colectiva, que se respalda en la homogeneidad de las comunidades y el análisis de los diferentes contextos (Laperrière y Zúñiga, 2007), pero sobre todo tiene en cuenta su carácter integral y dinámico (Mori, 2008).

El conocimiento de la comunidad, es un elemento fundamental constituyente del proceso de evaluación comunitaria, dado que es el punto de partida en cuanto a la apropiación de información que presenta cada habitante respecto a su comunidad (Vabi, 1996), y de la cual se derivan aspectos cruciales que determinan dicho conocimiento, tales como las necesidades comunitarias comprendidas por un déficit en el equilibrio o el funcionamiento 
de los aspectos comunitarios, surgiendo a partir de las problemáticas y los factores de riesgo con relación al entorno físico, las relaciones psicosociales y las necesidades de seguridad que son percibidas, las cuales permiten la toma de conciencia sobre los problemas o elementos que son obstáculo para el desarrollo social (Ibañéz, 2008).

De acuerdo al conocimiento de la comunidad y su conformación, Causse (2009), afirma que la comunidad necesita un área geográficamente específica, donde los habitantes suponen relaciones e interacciones de conocer, hacer y sentir, por el hecho de compartir aspectos comunes, que se dan en un ámbito social en el que se han desarrollado histórica y culturalmente intereses o necesidades, además según Arias (2015), su consolidación se extiende a un sistema social de raíz local y participativa; la comunidad entonces, está hecha de relaciones que junto con las acciones compartidas, con los miedos y las alegrías, sentidos y experiencias vividas otorga un asiento al recuerdo, un nicho a la memoria colectiva e individual; un ámbito determinado por circunstancias específicas, que desarrollan una forma de identidad social y construyen un sentido de comunidad (Montero, 2004), o el valor del colectivo (Sánchez y Del Pino, 2008). Estos elementos los diferencian de un grupo social (Sánchez, 2013), permitiendo la toma de conciencia de sí como comunidad y fortaleciéndose como unidad y potencialidad social. Es importante dentro de los procesos de evaluación comunitaria, el reconocimiento de las características propias de la comunidad, puesto que compartir sucesos o hechos históricos similares entre las personas ya sea de forma individual o grupal emerge sentimientos de unidad y pertenencia dentro de las dinámicas de construcción y participación comunitaria (Meza, 2009).

El proceso de evaluación comunitaria, es un elemento crucial que contribuye a identificar los aspectos positivos y negativos de los procesos en una comunidad, elementos que contribuyen al logro de los objetivos y puede orientar la mejora de la praxis (Pascual, 2007). De este modo, el proceso investigativo develó la existencia de dos problemáticas, la primera se relaciona con los prejuicios sociales, vistos como procesos grupales que reflejan percepciones positivas o negativas e influyen en las actitudes hacia determinados grupos (Pascale, 2010), es por eso que la comunidad evidencia que en primer lugar su ubicación geográfica, determina la construcción de un imaginario social negativo puesto que la comuna donde habitan se encuentra establecida en un sector en el que existen altos niveles de delincuencia, consumo y expendio de sustancias psicoactivas, deserción escolar y violencia barrial (Consejo Noruego para Refugiados, 2012), en segundo lugar el territorio hace parte de una de las comunas de la ciudad, donde se encuentra 
una confluencia de poblaciones con diversas problemáticas como pobreza, personas procedentes de diferentes procesos de reinserción, bajos niveles de empleabilidad y asesinatos de líderes sociales, factores que afianzan la creencia de marginalidad que se tiene hacia la comunidad y, en tercer lugar, los estereotipos se han internalizado dentro del imaginario colectivo de los miembros de la comunidad, lo cual ha provocado el reforzamiento de sentimientos de desesperanza frente a la búsqueda de oportunidades que les permitan mejorar sus condiciones de vida y bienestar integral, (Narváez, 2013).

Por otro lado, se evidencia la escases de trabajos académicos relacionados con la evaluación comunitaria como herramienta metodológica empleada en este tipo de comunidades, considerando que este tipo de estudios realizados con referencia a la evaluación comunitaria, pero sobre todo al sentido de comunidad, permiten obtener un panorama informativo acerca de los procesos comunitarios, teniendo en cuenta la diversidad de marcos contextuales, las particularidades de los procesos, sus componentes y sobre todo los aspectos metodológicos. Por ejemplo, en la investigación realizada por Ramos (2014) se hace énfasis en la importancia que los participantes dan a los sentimientos colectivos, dado que refieren que para sentirse parte de una comunidad no basta con el estar presente, sino que, el factor anímico juega un rol fundamental en el establecimiento de conexiones y lazos. De igual manera Gracia y Herrero (2006), determinaron que la percepción de apoyo social comunitario se encuentra relacionada positivamente con el ajuste psicológico, las condiciones de la comunidad y la percepción de apoyo comunitario de sus residentes. Mientras que Olivares y Reyes (2006) lograron profundizar en dimensiones técnicas, éticas y políticas necesarias para la construcción de un programa público.

Teniendo en cuenta los anteriores estudios, es importante agregar que últimamente el sentido de comunidad se ha convertido en un punto de investigación importante a nivel general, entre la comunidad científica, lo cual ha permitido una comprensión amplia y cultural del concepto. Sin embargo, los estudios no permiten conocer el proceso de evaluación comunitaria como una ruta metodológica que permite generar conocimiento a partir de la reflexión constante de los actores sociales. Este déficit teórico, práctico y social desde el panorama científico consolida el objeto de estudio de la investigación, ya que permite visualizar la necesidad de desarrollar el proceso de evaluación comunitaria, el cual debe ser el punto de partida para comprender fenómenos más complejos como la resiliencia y el sentido de comunidad. Además, la aproximación cualitativa no solo fortalece el acercamiento y la comprensión del fenómeno desde la propia comunidad (Laperrière y Zuñiga, 2007), sino 
que presenta una perspectiva holística considerando el fenómeno como un todo y no como un aspecto particular (Paramo, 2015).

De acuerdo con Rojas (2008), el proceso de evaluación comunitaria, cobra un significado y relevancia, cuando se lleva a la práctica, de la cual pueden surgir aspectos, que dan cuenta del estado de una comunidad y las formas de enfrentar la realidad, así como también el proceso se constituye como una fuente de reconocimiento e identificación para las personas, tal es el caso de los habitantes de la comunidad Arcoíris, pertenecientes a la comuna $10 \mathrm{del}$ municipio de San Juan de Pasto, quienes han sido actores en el denominado conflicto armado de Colombia (Centro Nacional de Memoria Histórica, 2013), y que por diferentes razones personales y sociales se enfrentaron a las fuerzas nacionales, es por eso que la investigación indagó acerca del resultado del proceso de evaluación comunitaria en los habitantes de la comunidad como una herramienta metodológica que permite la integración de sus miembros. El objetivo del estudio se orientó a desarrollar el proceso de evaluación comunitaria en los habitantes de la comunidad Arcoíris, quienes demuestran por medio de los logros alcanzados como comunidad, que existe la posibilidad de transformar los prejuicios sociales que se han construido desde $\mathrm{y}$ hacia su comunidad y también identificar por medio de las metas colectivas y la organización comunitaria, las estrategias de resiliencia efectivas ante las adversidades de su contexto (García y Domínguez, 2012), y así mejorar la cohesión personal, familiar y social, constituyéndose esta como una fuente de bienestar (Quintero, 2015).

\section{Método}

La presente investigación se desarrolla a través del paradigma cualitativo siendo pertinente para la comprensión de la realidad desde sus aspectos particulares (Quintana y Montgomery, 2006), el enfoque histórico hermenéutico, ya que posibilita la intercomunicación y la interacción considerando que las acciones de los sujetos no están reguladas por una ley, sino que nacen de la libertad y son susceptibles de interpretación y comprensión (Osorio, 2007; Muñoz et al. 2001, citados en Gómez \& Villalobos, 2014) y tipo de estudio fenomenológico, ya que otorga un lugar privilegiado a la subjetividad como fuente de conocimiento, de ahí el sustento de la presente investigación, dada la condición de permitir estudiar el fenómeno, por medio de la escucha atenta y la descripción detallada de cada evento para elaborar una estructura que represente dichas vivencias (Gómez y Villalobos, 2014). 
Se contó con la participación de 30 habitantes del barrio Sol de Oriente, etapa I, Comunidad Arcoíris, los cuales fueron seleccionados según criterios de pertenecer a la comunidad y manifestar la participación voluntaria. Asimismo, se contó con la participación de la presidenta y los miembros de la Junta de Acción Comunal del sector.

Las técnicas e instrumentos empleados fueron diseñados tomando como referente las categoría de la evaluación comunitaria, es decir conocimiento, entorno físico, historia, características, organización, necesidades y recursos, de los cuales se derivan las dimensiones, además cada uno de los instrumentos se sometió a evaluación de un experto, tomando como referencia los criterios de claridad, pertinencia, suficiencia e importancia antes de llevarse a la práctica. De igual manera para la aplicación de las técnicas e instrumentos, fue necesario relacionarlos con las categorías, en este sentido en la observación participante, por medio del diario de campo, se identificaron elementos como: condiciones físicas de la comunidad, sentimientos, actitudes y percepciones de los habitantes cuando se llevaron a cabo las diferentes encuentros, más adelante se empleó la entrevista semiestructura para analizar el conocimiento, que presentaban los actores y trayectoria histórica, seguidamente se desarrolló el mapeo comunitario con el fin de hacer un recorrido por la comunidad y vislumbrar su entorno físico, posteriormente se desarrolló un grupo focal, en el que se indagaron aspectos en función de los procesos de organización comunitaria y por último se trabajaron a través de la herramienta DRAFPO (debilidades, recursos, amenazas, fortalezas, potencialidades y oportunidades) las necesidades, recursos, debilidades, oportunidades, fortalezas y amenazas.

El procedimiento se desarrolló inicialmente mediante la familiarización o acercamiento con los habitantes de la comunidad y con su entorno físico con el fin de dar inicio a una etapa de reconocimiento entre actores. Más adelante se presentaron los permisos por parte de la universidad y los miembros de la Junta de Acción Comunal (JAC) para poder dar inicio no solo a la recolección de información, sino al desarrollo de los encuentros; además, como consideraciones éticas se contó con la supervisión de expertos en cada fase del proceso y la comprensión de los procedimientos, elementos claves al momento de diligenciar los respectivos consentimientos informados. Por otra parte, se tuvo en cuenta la disponibilidad de los habitantes y las reuniones de la Junta de Acción Comunal con toda la comunidad, así como también de la facilidad para aplicar las técnicas, dadas las condiciones climáticas.

Después se analizó la información a través del Software ATLAS ti.lnk versión7, el cual fue propicio para organizar la información recolectada, 
transcribir los resultados, construir las categorías de análisis y triangular o analizar los datos. Por último, fue necesario someter todo el proceso a la evaluación comunitaria, es decir que, con los resultados obtenidos y las informaciones brindadas, se contrastan los resultados con la realidad percibida por los investigadores, teniendo en cuenta las diferentes opiniones que se presentaron, así como también salvaguardando los derechos de los participantes y el manejo de la información.

\section{Resultados}

A continuación se presentan los resultados obtenidos durante el proceso, inicialmente se evidencia la red semántica obtenida a través del software Software ATLAS ti.lnk versión7, que relaciona las categorías del proceso de evaluación comunitaria y posteriormente en análisis de cada categoría.

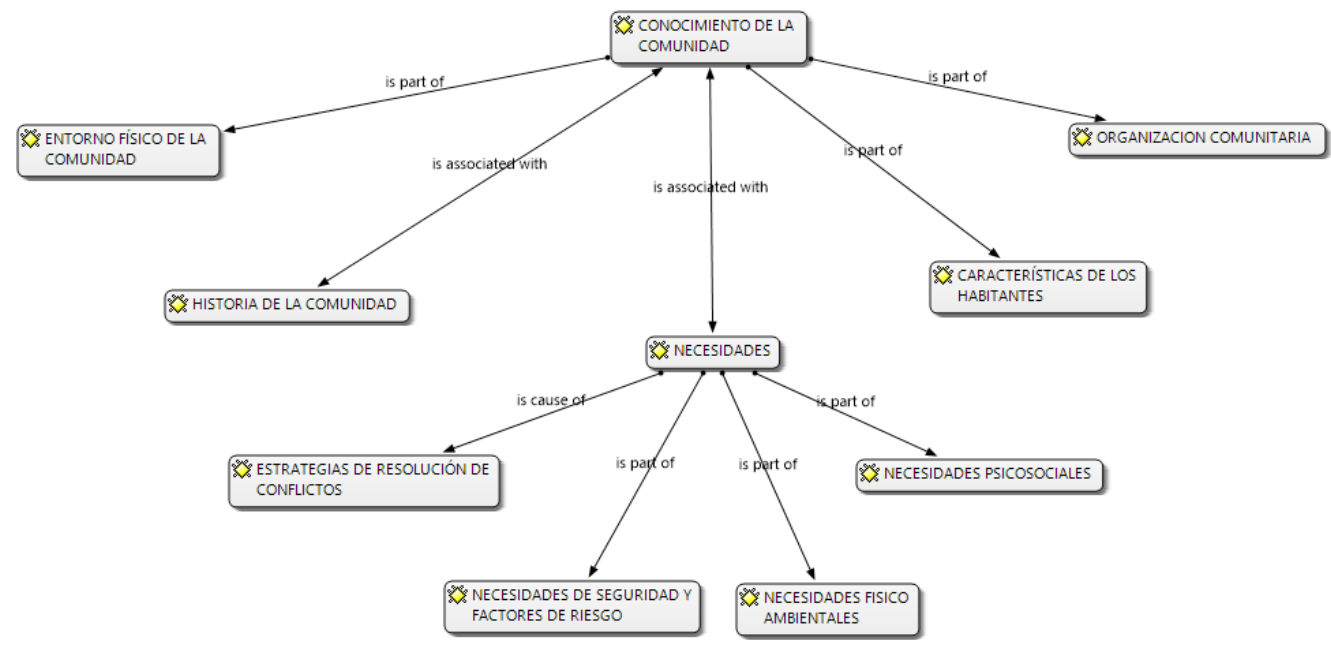

Figura 1. Red Semántica Categorías de Análisis Evaluación Comunitaria.

Fuente: Propia

\section{Conocimiento de la Comunidad}

Se logra evidenciar que el conocimiento de la comunidad, se fortalece desde el aporte individual y colectivo, como una construcción social determinada por el conjunto de subjetividades desde una perspectiva de comunidad. En ese sentido, se identifica que los habitantes de la comunidad relacionan 
diferentes aspectos que constituyen dicho conocimiento, los cuales significan la relación de los sujetos con el entorno físico, la historia, sus necesidades y recursos, características de los habitantes y la organización comunitaria como parte de la construcción colectiva de su contexto.

\section{Entorno físico de la comunidad}

La comunidad Arcoíris manifestó conocimientos fundamentales sobre los aspectos físicos, reconociendo el entorno como un componente crucial para el desarrollo del sentido de comunidad en sus integrantes. Los habitantes identifican como puntos a destacar, los medios de transporte y las vías de acceso dada su ubicación geográfica en la ciudad; además las condiciones del barrio, principalmente en pavimentación, acceso a servicios públicos y organización del sector en general ya que a partir de ello se han generado estrategias de acción colectivas. Este reconocimiento físico aludió la importancia dentro de la evaluación comunitaria que tiene la identificación de lugares estratégicos como el salón comunal y el parque, siendo el primero un referente indispensable que posibilita los encuentros de la comunidad y ante el cual se manifiestan orgullosos, dada la significancia para su historia pues manifiestan que es resultado del trabajo en comunidad en el proceso de construcción del barrio, de ese modo se destaca la autogestión característica de los habitantes al realizar tareas y actividades con el fin de mejorar los diferentes espacios. Por lo anterior, la comunidad destaca la importancia de la caracterización del entorno físico, ya que brinda un alto grado de apropiación sobre el barrio, fortalece la identidad territorial y promueve el bienestar social.

Se reconoce, entonces, que la comunidad ha generado y compartido un territorio como escenario donde se llevan a cabo las acciones y los procesos, permitiendo la creación de actitudes prosociales entre sus miembros, por ejemplo: la solidaridad y el sentimiento de compartir una historia en común, resultado de su proceso luego de dejar las armas y en mejora de su calidad de vida, teniendo en cuenta la construcción de memoria histórica que promueve lazos de fraternidad y reconociendo la necesidad de hacer de éste un proceso intergeneracional.

\section{Historia de la comunidad.}

Se identifica que los participantes reconocen la historia de su comunidad como un eje fundamental de construcción comunitaria, ya que el barrio se consolida como una propuesta de proyección social del Estado donde la mayor parte de sus habitantes provenían de grupos al margen de la ley. Además, los sujetos fundadores afirman que la construcción de la asociación 
denominada Arcoíris, es una forma de resignificar su proyecto de vida para promover el sentido de fraternidad y similitud entre sus habitantes, ya que comparten con orgullo el trabajo de construir el sector y el origen de la comunidad, permitiendo la consolidación de tejido social. Lo anterior, se reconoce como una forma de analizar los diferentes procesos de la comunidad ante las problemáticas y las necesidades, tal como lo afirman los habitantes; sin embargo, la comunidad hace énfasis que éstos son una consecuencia del constante crecimiento urbanístico de la ciudad.

\section{Características de los habitantes}

La mayoría de los habitantes se refieren de forma positiva hacia los demás miembros, sin embargo, en sus dinámicas relacionales consideran la importancia de generar mejores canales de comunicación para optimizar y promover las dinámicas de participación y construcción colectiva. Se evidencia la capacidad de los habitantes de analizar y evaluar su realidad de forma sincera y objetiva, lo cual les permite construir un conocimiento comunitario sólido y coherente con las metas y los proyectos, desde la identificación de su historia, sus problemáticas y posibles alternativas de solución; lo anterior acompañado de la capacidad de apertura al cambio, puesto que consideran que es un factor que direcciona todo proceso comunitario y les proporciona seguridad y bienestar.

Es indispensable mencionar el sistema de valores y actitudes característicos de sus habitantes, ya que la mayoría perciben que los miembros se destacan por el desarrollo de valores como fraternidad, respeto y tolerancia enmarcados hacia las diferencias de pensamiento, creencia o cultura y la amistad como el componente unificador de las conductas prosociales. Los agentes consideran que las características de los habitantes no son homogéneas y absolutas a todos los miembros, ya que se pueden percibir diferentes niveles de expresión, por lo que en ocasiones las dinámicas de organización comunitaria se encuentran obstaculizadas por la ausencia de un sistema de comunicación eficaz que posibilite y fomente la asistencia de otros miembros de la comunidad, generalmente los "vecinos más nuevos".

\section{Organización comunitaria}

Los habitantes de la comunidad Arcoíris, manifiestan que la resiliencia es un factor común, al afirmar que a pesar de las condiciones de indiferencia estatal han podido sobreponerse a las adversidades en el desarrollo de procesos psicosociales de integración entre los habitantes, así como con las condiciones físicas y de bienestar. De ese modo, la organización comunitaria ha sido 
la forma crucial de fomentar acciones comunitarias con el fin de apostar al cambio y a la transformación de su realidad para mejorar su calidad de vida.

Se identifica que la cohesión grupal y las características de los individuos le han propiciado logros a la historia comunal, uno de ellos, es la conformación de la Junta de Acción Comunal (JAC) y su reconocimiento a nivel municipal, la cual ha facilitado escenarios de avance y empoderamiento del sector, ya que su gestión convoca a la participación de la comunidad, así como el establecimiento de vínculos interinstitucionales, permitiendo la adquisición de recursos como la obra del alcantarillado público y el mantenimiento del parque. Además, afirman que la organización comunitaria ha conllevado a la construcción de uno de los espacios físicos más importantes, el salón comunal, el cual les han permitido llevar a cabo los encuentros de reconocimiento, fraternidad y planificación.

\section{Necesidades comunitarias}

La aplicación de las técnicas e instrumentos permitieron identificar las necesidades existentes agrupándolas en dos dimensiones: Físico-ambientales y Psicosociales, develando los recursos que dentro de la comunidad existen como oportunidad de generar procesos colectivos (ver Tabla 1).

\section{Tabla 1. Necesidades y recursos comunitarios}

\begin{tabular}{|c|c|c|}
\hline & NECESIDADES & RECURSOS \\
\hline \multirow{4}{*}{ Físico-ambiental } & \multirow{4}{*}{$\begin{array}{l}\text { - Incentivar a las generaciones más jóvenes a } \\
\text { preservar los recursos físicos y cuidarlos de } \\
\text { usos no apropiados. }\end{array}$} & $\begin{array}{l}\text { - Reconocimiento del par- } \\
\text { que y el salón comunal } \\
\text { como un elemento fun- } \\
\text { damental dado su valor } \\
\text { simbólico y estratégico de } \\
\text { encuentro. }\end{array}$ \\
\hline & & $\begin{array}{l}\text { - Documentos y registros } \\
\text { fotográficos que con- } \\
\text { tienen la historia de la } \\
\text { comunidad (fotografías } \\
\text { y periódicos) }\end{array}$ \\
\hline & & $\begin{array}{l}\text { - Interés de varios agentes } \\
\text { de la comunidad por rea- } \\
\text { lizar encuentros y mingas } \\
\text { para el mantenimiento } \\
\text { del barrio. }\end{array}$ \\
\hline & & $\begin{array}{l}\text { - Habilidad de líderes } \\
\text { comunitarios para la } \\
\text { gestionar recursos. }\end{array}$ \\
\hline
\end{tabular}




\begin{tabular}{|c|c|c|}
\hline & NECESIDADES & RECURSOS \\
\hline Psicosociales & $\begin{array}{l}\text { - Potencializar dinámicas participativas, que } \\
\text { permitan el fortalecimiento de la identidad } \\
\text { y pertenencia de la comunidad. } \\
\text { - Dar a conocer la historia de la comunidad } \\
\text { a las nuevas generaciones por parte de los } \\
\text { líderes y habitantes de la comunidad que } \\
\text { participaron en el proceso de construcción } \\
\text { del barrio. } \\
\text { - Incentivar a los comités de la JAC a trabajar } \\
\text { y retomar procesos con el fin de generar un } \\
\text { bienestar colectivo. } \\
\text { - Fortalecer sus vínculos a través de } \\
\text { estrategias que contribuyan a la } \\
\text { comunicación por medio de la difusión de } \\
\text { información. } \\
\text { - Generar espacios intergeneracionales } \\
\text { de cultura, recreación, socialización } \\
\text { y aprendizaje, que visibilice las } \\
\text { potencialidades y talentos de los habitantes } \\
\text { del barrio. } \\
\text { - Los habitantes afirman que el parque se ha } \\
\text { convertido en un centro de concentración } \\
\text { para actividades ilícitas como el consumo } \\
\text { de Sustancias psicoactivas por parte de } \\
\text { agentes externos a la comunidad. }\end{array}$ & $\begin{array}{l}\text { - Auto reconocimiento } \\
\text { de competencias y } \\
\text { aptitudes subjetivas } \\
\text { que contribuyen a la } \\
\text { consolidación y ejecución } \\
\text { efectiva de los diferentes } \\
\text { procesos comunitarios. } \\
\text { - Actitudes pro sociales } \\
\text { entre vecinos. } \\
\text { - Espacios de reflexión de } \\
\text { la comunidad por medio } \\
\text { de las reuniones de la } \\
\text { JAC. } \\
\text { - Habilidades artísticas, } \\
\text { deportivas y de liderazgo } \\
\text { en las diferentes } \\
\text { generaciones de } \\
\text { habitantes del barrio. }\end{array}$ \\
\hline
\end{tabular}

Con relación a la aplicación de la técnica Debilidades, Recursos, Amenazas, Fortalezas, Potencialidades y Oportunidades (DRAFPO) permitió a la comunidad hacer un análisis de reconocimiento de sí mismos, esta presenta los siguientes datos (ver Tabla 2).

\section{Tabla 2. Resultados DRAFPO}

\begin{tabular}{|c|c|c|c|}
\hline DE & & IS & le \\
\hline $\begin{array}{l}\text { •Baja asistencia a re- } \\
\text { uniones de la JAC. } \\
\text { - Temor a asumir } \\
\text { responsabilidades } \\
\text { con los procesos de } \\
\text { la comunidad. } \\
\text { - Dificultad en los ca- } \\
\text { nales y estrategias } \\
\text { de comunicación. }\end{array}$ & $\begin{array}{l}\text {-Desarrollar estrategias } \\
\text { de convocatoria (engan- } \\
\text { che) para incrementar la } \\
\text { asistencia. } \\
\text { • Crear espacios que forta- } \\
\text { lezcan los vínculos entre } \\
\text { los vecinos. } \\
\text { - Generar compromisos es- } \\
\text { pecíficos por cada agente. } \\
\text { - Desarrollar y fortalecer } \\
\text { canales de comunicación. }\end{array}$ & $\begin{array}{l}\text { - Acceso a educación. } \\
\text { - Capacidad de auto- } \\
\text { gestión. } \\
\text { - Liderazgo. } \\
\text { - Sentido de pertenen- } \\
\text { cia. } \\
\text { - Resiliencia frente a } \\
\text { problemáticas de la } \\
\text { comunidad. }\end{array}$ & $\begin{array}{l}\text { - } \text { Promover } \\
\text { estrategias de } \\
\text { participación que } \\
\text { motiven a la JAC a } \\
\text { continuar con los } \\
\text { procesos. } \\
\text { - Desarrollar es- } \\
\text { pacios reflexivos } \\
\text { que fomenten } \\
\text { la participación } \\
\text { comunitaria. }\end{array}$ \\
\hline
\end{tabular}




\begin{tabular}{|c|c|c|c|}
\hline RESISTENCIAS & Se propone & POTENCIALIDADES & Se propone \\
\hline $\begin{array}{l}\text { - Crítica de algunos } \\
\text { miembros de la } \\
\text { comunidad frente a } \\
\text { procesos de la JAC }\end{array}$ & $\begin{array}{l}\text {-Desarrollar espacios } \\
\text { reflexivos que fomenten } \\
\text { la práctica de valores } \\
\text { comunitarios. }\end{array}$ & $\begin{array}{l}\text { • Nuevos líderes comu- } \\
\text { nitarios. } \\
\text { • Red de apoyo comu- } \\
\text { nitaria. } \\
\text { •Espacios de integra- } \\
\text { ción comunitaria. }\end{array}$ & $\begin{array}{l}\text { - Desarrollar espa- } \\
\text { cios reflexivos que } \\
\text { vinculen nuevos } \\
\text { puntos de encuen- } \\
\text { tro. }\end{array}$ \\
\hline AMENAZAS & Se propone & OPORTUNIDADES & Se propone \\
\hline $\begin{array}{l}\bullet \text { Consumo y ex- } \\
\text { pendio de SPA por } \\
\text { agentes externos. } \\
\text { • Prejuicio social } \\
\text { externo. } \\
\text { •Embarazo en ado- } \\
\text { lescentes. }\end{array}$ & $\begin{array}{l}\text { - Generar compromisos u } \\
\text { acciones que permitan ac- } \\
\text { tivar redes de seguridad, } \\
\text { educación y convivencia. }\end{array}$ & $\begin{array}{l}\text { - Salón comunal. } \\
\text { • Junta de Acción Co- } \\
\text { munal (Organización } \\
\text { de comités). } \\
\text { - Talentos artísticos. } \\
\text { - Parque recreativo. }\end{array}$ & $\begin{array}{l}\text { - Motivar a los } \\
\text { miembros de la } \\
\text { comunidad sobre } \\
\text { la importancia del } \\
\text { aprovechamiento } \\
\text { de recursos físicos } \\
\text { y humanos. }\end{array}$ \\
\hline
\end{tabular}

Fuente: Propia

\section{Discusión}

Teniendo en cuenta que el objetivo general del estudio fue realizar el proceso de evaluación comunitaria en los habitantes del sector Sol de Oriente Etapa 1 Comunidad Arcoíris, es fundamental reconocer las relaciones existentes entre las categorías o dimensiones de la evaluación comunitaria donde el conocimiento de la comunidad es el elemento del cual se construyen una diversidad de procesos comunitarios, en los que se resalta que el entorno físico de la comunidad, las características de los habitantes y la organización comunitaria son indispensables para promover la apropiación de la información de cada habitante, tal y como lo afirma Vabi (1996). En cuanto a las dimensiones historia de la comunidad y necesidades se encuentran asociadas a la dimensión conocimiento comunitario, siendo esta última el elemento que permitió develar el estado de la comunidad respecto a las estrategias de resolución de conflictos, necesidades de seguridad y factores de riesgo, necesidades físico ambientales y necesidades psicosociales, las cuales permiten la toma de conciencia sobre las oportunidades de mejora (Ibáñez, 2008). Estos elementos evidencian la importancia del diagnóstico en las comunidades, puesto que dadas sus dinámicas de transformación resulta imprescindible el desarrollo constante de la conciencia histórica que fomente la acción colectiva, tal como lo propone Laperrière y Zúñiga (2007). 
De igual forma, sus costumbres, como la celebración de fechas especiales, es el caso de la celebración del 31 de octubre y la novena navideña, promueven la integración, ya que a través de sus festividades consolidan la red comunitaria y comparten espacios que los identifican como una comunidad ejemplo para otras, corroborando lo expuesto por Causee (2009), al afirmar la necesidad de una área geográficamente específica para la comunidad y sus miembros que posibilita escenarios de cohesión social a fin de generar estrategias colectivas. Se destacan las formas lingüísticas propias de la comunidad, que parten de la similitud que han desarrollado y que favorecen la comunicación, así como también el análisis de su realidad y, por consiguiente, la creación de recursos de afrontamiento que han brindado solución a sus problemas, principalmente la consolidación y legalización de la junta de acción comunal, aspectos que, tal como lo afirma Ibáñez (2008), permiten la toma de conciencia de aspectos que limitan el desarrollo social dentro de la comunidad.

En concordancia con lo postulado por Montero (2004), al afirmar que la comunidad supone relaciones e interacciones de hacer, conocer y sentir, las cuales se dan en un ámbito social desarrollado histórica y culturalmente, y que por circunstancias específicas desarrollan una forma de identidad social dada esa historia compartida y posibilitando la construcción de un sentido de comunidad, se reconoce que la comunidad presenta una forma de desarrollo particular, puesto que desde sus orígenes, los integrantes le apuestan a la construcción de un cambio positivo, que presenta como objetivo la construcción de la paz, vista desde el ejemplo de una comunidad en desarrollo y en constante evolución, que analiza y hace frente a sus realidades.

Por otra parte, y en relación con Vabi (1996), al postular que el conocimiento posibilita el saber comunitario, se afirma que éste se presenta en aspectos generales propios de los habitantes, por ejemplo, el reconocimiento y la importancia que tiene la Junta de Acción Comunal, el desarrollo de su infraestructura y las características de la mayoría de los miembros. También puede ser controvertido ya que los resultados evidencian que el conocimiento se encuentra en aquellos lideres o personas claves que conforman a la comunidad, mientras que se desconoce descripciones acerca de las características de miembros más recientes, lo que probablemente se constituya en una negativa de apertura frente a nuevas experiencias que se puedan presentar en la comunidad, así como también se puede estar frente al desinterés o pérdida de valores que fomenten las acciones comunitarias, debido a lo heterogeneidad de sus habitantes. Para Molina (2005), las dificultades en el desarrollo de procesos de dialogo, se debe a la perspectiva de autoridad que se tenga de los lideres, de ahí que el silencio e indiferencia de los demás miembros, se 
convierte en una respuesta e incluso en una forma de resistencia comunitaria que afecta significativamente los procesos, pero que invita a generar nuevas reflexiones acerca de la participación y la imagen de los líderes.

Además, es primordial reconocer que sus miembros comparten una historia en común, lo que ha significado un sentimiento de compartir experiencias, principalmente su participación en el conflicto armado, permitiendo resignificar su realidad y sobreponerse a ella por medio de la resiliencia, así como también se desarrollan como una adaptación efectiva que busca el bienestar común (García y Domínguez, 2012). De ello que se logró el reconocimiento por parte de la comunidad frente al proceso de evaluación comunitaria, puesto que en concordancia con Rojas (2009), permitió que el análisis de aspectos cotidianos desde la subjetividad y la colectividad, de paso a la identificación por sí mismos el estado de su comunidad y las formas de enfrentar la realidad.

Por lo anterior, es posible postular que tales procesos han viabilizado la generación y potencialización de aquellos recursos propios de su comunidad, por ejemplo la construcción del salón comunal como espacio de encuentro, integración y participación comunitaria así como la obra del alcantarillado, los cuales solventan sus necesidades y contribuyen a mejorar la calidad de vida de los miembros, tal como lo afirma Fuster, Lorenas y Salgado (2015), pero que sobre todo lucha contra con el olvido (Latorre, 2012), favoreciendo las ideas de Nasi y Rettberg (2006), donde existe una disminución en el número de conflicto, pero un aumento significativo en los procesos de resiliencia.

Por último, y siguiendo la línea de Ibañéz (2008), la evaluación de las necesidades surge como una respuesta a la constante retroalimentación que realiza la comunidad de su trayectoria y que da cuenta de los desequilibrios que se han presentado a lo largo de la construcción, es decir que ésta brinda elementos a la hora de determinar las relaciones psicosociales como el reconocimiento de actitudes prosociales, como el liderazgo, entre los habitantes y las necesidades en materia de seguridad, por ejemplo: la identificación de agentes externos a la comunidad que han llegado a consumir sustancias psicoactivas en espacios comunes como el parque, sin embargo, la evaluación de las necesidades puede ser el camino inicial para encaminar acciones a futuro que permitan solventar, así como también activar nuevos recursos o rutas para hacer frente a ellas.

\section{Conclusiones}

La evaluación comunitaria es una herramienta fundamental que permite a partir de su metodología realizar procesos investigativos, al posibilitar un 
acercamiento profundo a la comprensión de los fenómenos que se desarrollan dentro de una comunidad, el humanizar y el generar espacios reflexivos que confrontan los postulados teóricos y la realidad subjetiva, permitiendo una mayor comprensión de la realidad al ser direccionada por los mismos actores, por tanto consolida la práctica frente al qué hacer de la psicología comunitaria.

A partir del proceso de evaluación comunitaria que se realizó con los habitantes del Sector Sol de Oriente Etapa 1, es imprescindible reconocer en primer lugar el potencial que tienen los seres humanos para conformar grupos y consolidar comunidades, partiendo de historias comunes que emergen como alternativas de cambio y reflexión frente a un contexto demandante, que sugiere un equilibrio entre variables individuales y grupales. De igual manera la comunidad habla desde su sentir y desde su experiencia frente a la percepción de lo social, visto como la construcción de un tejido que permite servir de sostén a los miembros y que avanza conforme a las necesidades y los recursos que se adquieren a lo largo del tiempo, ya que desde su consolidación se encamina hacia la construcción de un conjunto de sentimientos, actitudes, acciones y formas de comunicación para transformar los prejuicios sociales que se han construido a través de su historia de vida y su participación dentro del conflicto armado colombiano.

Al mismo tiempo, la construcción de una comunidad genera cambios en la estructura social de un territorio, ya que en su habitar, se deja claro que hay un interés indiscutible en promover la vida social y comunitaria a partir de sentimientos de cohesión y desinterés individual, que al finalizar sirven como ejemplo de desarrollo social para otras comunidades en proceso de construcción o que atraviesan por circunstancias similares.

Es importante mencionar que los sujetos expuestos a situaciones adversas, como el conflicto armado de Colombia, han fomentado cambios a nivel individual y grupal, expresados con similitud en las diferentes partes que lo conforman, puesto que el conflicto es una posibilidad que invita a generar cambios estructurales frente a cómo percibe el ser humano la diferencia del otro, pero sobre todo cómo este proceso pone a prueba los recursos con los que cuenta el ser humano para realizar sus propios cambios y construir una mejor sociedad.

\section{Agradecimientos}

Al programa de Psicología de la Universidad de Nariño, por su acompañamiento imprescindible en la formación de prácticas académicas que apoyan los procesos de interacción social. A los miembros de la comunidad Arcoíris por su calidez y apoyo incondicional en el proceso. 


\section{Conflicto de intereses}

Los autores declaran que no se presentó ningún conflicto de interés.

\section{Referencias}

Aliste, E., Almendras, A., Contreras, M. (2012). La dinámica del territorio en la conurbación Concepción-Talcahuano: huellas urbanas para una interpretación de las transformaciones ambientales durante la segunda mitad del siglo XX. Revista de geografía Norte Grande, No (52): 5-18. Recuperado de http://www.scielo.cl/ scielo.php?script $=$ sci_arttext\&pid $=$ S0718-34022012000200001.

Arias, M., (2015). Psicología comunitaria: posibilidades y opacidades. Psicogente, 18(34): 253 - 259. Recuperado de http://www.scielo.org.co/scielo. php?sdecript $=$ sci_arttext\&pid $=$ S0124-01372015000200001.

Carroll, A., Pérez, M. (2004). Elaborando una evaluación de la comunidad. Los Angeles, USA. Revista Center for Health Policy Research, Health DATA Program. Recuperado de http://healthpolicy.ucla.edu/programs/health-data-espanol/ Documents/curriculo_elaborandounaevaluacion.pdf.

Causse, M. (2009). El concepto de comunidad desde el punto de vista socio -históricocultural y lingüístico. Ciencia en su PC, 3: 12-21. Recuperado de http://www. redalyc.org/articulo.oa?id $=181321553002$

Centro de Nacional de Memoria Histórica (2013). Informe general los orígenes, las dinámicas y el crecimiento del conflicto armado en Colombia. Colombia. Recuperado de http://centrodememoriahistorica.gov.co/descargas/informes2013/bastaYa/ capitulos/basta-ya-cap2_110-195.pdf.

Consejo Noruego para Refugiados (2013). Informes de integración territorial, Base de datos Secretaria de Desarrollo Social San Juan de Pasto. Documento sin publicar.

Díaz, L., Torruco, U., Martínez, M., Varela, M. (2013). La entrevista, recurso flexible y dinámico. Investigación en Educación Médica, 2 (7): 162-167. Recuperado de: http://www.redalyc.org/articulo.oa?id=349733228009

Fuster, X., Lorenas, M., Salgado, J. (2015). Enfrentar los desastres socionaturales desde los capitales y recursos comunitarios: el caso de la erupción volcánica de Chaitén, Chile. Revista Magallania, 43(3): 125-139. Recuperado de http://www. scielo.cl/scielo.php?script $=$ sci_arttext\&pid=S0718-22442015000300010.

García, M., Domínguez, E. (2012) Desarrollo teórico de la Resiliencia y su aplicación en situaciones adversas: Una revisión analítica, Cinde-Universidad de Manizales, 
Colombia. Revista Latinoamericana de Ciencias Sociales, Niñez y Juventud, 11 (1): 63-77. Recuperado de http://www.redalyc.org/articulo.oa?id=77325885001

Gracia, E., Herrero, J. (2006). La comunidad como fuente de apoyo social: evaluación e implicaciones en los ámbitos individual y comunitario. Revista Latinoamericana de Psicología, 38(2): 327-342. Recuperado de http://pepsic.bvsalud.org/scielo. php?script $=$ sci_arttext\&pid $=$ S0120-05342006000200007\&lng $=$ pt\&tlng $=e s$.

Gómez, A., Villalobos, F. (2014). Competencias para la formulación de un proyecto de Investigación. Guía metodológica del proyecto INVESTIC para docentes investigadores. Colombia, San Juan de Pasto: Editorial Universidad de Nariño.

Hombrados, I., López, T. (2014). Dimensiones del sentido de comunidad que predicen la calidad de vida residencial en barrios con diferentes posiciones socioeconómicas. Psychosocial Intervention, 23(3): 159-167. Recuperado de https://dx.doi.org/10.1016/j.psi.2014.08.001-

Ibañéz, C. (2008). Participación comunitaria y diagnóstico de necesidades (Blog). Recuperado de http://www.madrimasd.org/blogs/salud_ publica/2008/11/17/107090.

Latorre, E. (2010) Memoria y resiliencia: Estudio de la memoria de las víctimas del conflicto armado en el departamento del magdalena: presentificación, visibilización, catarsis y resiliencia. Prolegómenos. Derechos y Valores, 13 (25): 95-109. Recuperado de https://www.redalyc.org/articulo.oa?id=87617271006

Laperrière, H., Zúñiga, R. (2007). Cuando la comunidad guía la acción: hacia una evaluación comunitaria alternativa. Psicologia \& Sociedades, 19(3): 39-45. Recuperado de https://dx.doi.org/10.1590/S0102-71822007000300007

López, O. (2004). La resiliencia de las familias afectadas por el desplazamiento forzado en Colombia. Revista Perspectivas Sociales, 7 (2): 17-22. Recuperado de https://dialnet.unirioja.es/servlet/articulo?codigo $=5018843$

Martínez, A. (2007). La observación y el diario de campo en la definición de un tema de Investigación. Revista Perfiles Libertadores, 1(9): 74-80, Recuperado de: https:// escuelanormalsuperiorsanroque.files.wordpress.com/2015/01/9-la-observacin-yel-diario-de-campo-en-la-definicin-de-un-tema-de-investigacin.pdf

Meza, G. (2009). Comunidad y sentido de comunidad. Universidad de Chile (Tesis de pregrado). Universidad de Chile, Santiago, Chile. http://www.tesis.uchile.cl/ tesis/uchile/2009/cs-meza_g/pdfAmont/cs-meza_g.pdf

Molina, N. (2005). Resistencia comunitaria y transformación de conflictos. Reflexión Política, 7 (14), 70-82. Recuperado de https://atheneadigital.net/article/view/ n6-molina/175-html-es 
Montero, M. (2004). Introducción a la psicología comunitaria. Desarrollo, conceptos y procesos. Buenos Aires: Editorial Paidós. Recuperado de http://saber.ucv.ve/ jspui/bitstream/123456789/4207/1/montero-introduccion-a-la-psicologiacomunitaria

Narváez, J. (2013). Violencia barrial, la tensión social como crisis humanitaria. Revista Tesis Psicológica, 8(1): 56-67. Recuperado de file:///C:/Users/Psicologia\%201/ Downloads/Dialnet-ViolenciaBarrialLaTensionSocialComoCrisisHumanit ar-4630274.pdf

Nasi, C., Rettberg, A. (2005). Los estudios sobre conflicto armado y paz: un campo en evolución permanente. Colombia Internacional, 62(1): 65-85. Recuperado de https://revistas.uniandes.edu.co/doi/pdf/10.7440/colombiaint62.2005.04

Olivares, B., Reyes, M. (2016). Evaluación de un programa de social en infancia desde los principios de la psicología comunitaria. Revista Latinoamericana de Ciencias Sociales, Niñez y Juventud, 14 (1), 431-444. Recuperado de http://www.scielo. org.co/pdf/rlcs/v14n1/v14n1a30.pdf.

Pascale, P. (2010). Nuevas formas de racismo: Estado de la cuestión en la psicología social del prejuicio. Revista Ciencias Psicológicas, 4(1): 57-69. Recuperado de http://www.scielo.edu.uy/pdf/cp/v4n1/v4n1a06.pdf

Pascual, B. (2007). La evaluación de la intervención comunitaria: un marco para la reflexión Pedagogía Social. Revista Interuniversitaria, 14: 129-138. Recuperado de: http://www.redalyc.org/pdf/1350/135012681010.pdf

Páramo, D. (2015). La teoría fundamentada (Grounded Theory), metodología cualitativa de investigación científica. Revista Pensamiento \& Gestión, 39: 1-7. Recuperado de http://www.scielo.org.co/scielo.php?script=sci_ arttext\&pid $=$ S1657 62762015000200001\&lng $=$ en\&tlng $=$ es.

Quintana, A., Montgomery, W. (Eds.) (2006). Psicología: Tópicos de actualidad. Lima: UNMSM. Recuperado de https://cienciassociales.webcindario.com/PDF/ Cualitativa/Inv_quintana.pdf

Quintero, A. (2005). Resiliencia: Contexto no clínico para trabajo social. Revista Latinoamericana de Ciencias Sociales, Niñez y Juventud, 3(1): 73-94. Recuperado de http://www.scielo.org.co/scielo.php?script=sci_arttext\&pid=S1692715X2005000100004.

Ramos, C. (2014). Sentido de Comunidad en Movimiento Scout: Contribución a la colectividad en la Sociedad. (Tesis de pregrado). Universidad del Bio-Bio, Región Chillán, Chile. http://repobib.ubiobio.cl/jspui/bitstream/123456789/224/1/ Ramos\%20Salazar_Cesar\%20E..pdf 
Rojas, D. (2009). Resiliencia frente a la violencia política en instituciones educativas de dos ciudades andinas. Informe Final. Lima, Perú. Recuperado de https://www.mcgill. ca/traumaglobalhealth/files/traumaglobalhealth/InformeResilienciaAndinas.pdf.

Sánchez, A. (2013). ¿Es posible el empoderamiento en tiempos de crisis? Repensando el desarrollo humano en el nuevo siglo. Universitas Psychologica, 12 (1): 285-300. Recuperado de http://www.redalyc.org/articulo.oa?id=64728729025.

Sánchez, L., Del Pino, M. (2008). Una mirada a la participación comunitaria en el proceso de contraloría social. Revista Paradigma, 29 (2):35-53. Recuperado de http://www. scielo.org.ve/scielo.php?script $=$ sci_arttext\&pid $=$ S1011-22512008000200003.

Vabi, M. (1996). Alcanzando el conocimiento y saber comunitario sobre los usos de los árboles con métodos de Diagnóstico Rural Participativo. Recuperado de https:// www.odi.org/sites/odi.org.uk/files/odi-assets/publications-opinion-files/1532. pdf. 